\title{
Descentralização das atividades de Pesquisa, Desenvolvimento e Engenharia de empresas transnacionais: uma investigação a partir da perspectiva de subsidiárias automotivas
}

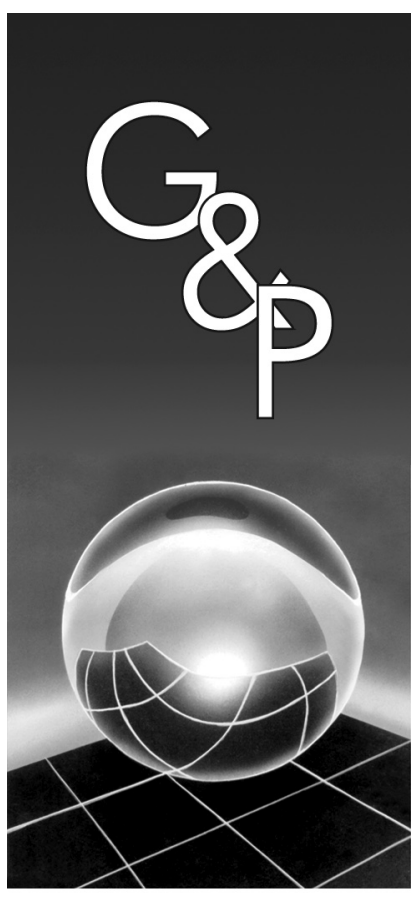

Ana Valéria Carneiro Dias

Mario Sergio Salerno

\begin{abstract}
Resumo
A descentralização de atividades de Pesquisa, Desenvolvimento e Engenharia $P, D \& E$ de empresas transnacionais tem sido explicada a partir de condições de mercado $e$ de acesso a recursos escassos. Tais análises são baseadas em países centrais - ou seja, empresa transnacional originária de um país central estabelecendo centro de $P, D \& E$ em outro país central -, e não explicam adequadamente a locação desses centros em países emergentes como o Brasil. A partir de estudo em profundidade na indústria automobilística brasileira, com pesquisa em subsidiárias aqui localizadas e nas suas matrizes no exterior, propomos uma adequação na teoria explicativa para tal descentralização. Ao lado das explicações tradicionais - necessidade de proximidade do mercado e busca por tecnologias não existentes nos centros de inovação - propomos que a descentralização das atividades de $P, D \& E$ em direção a subsidiárias é influenciada pela necessidade de agilizar o desenvolvimento de produtos e pela qualidade das relações entre matriz e subsidiária.
\end{abstract}

Palavras-chave: Pesquisa e Desenvolvimento $(P \& D)$. Desenvolvimento de produto. Descentralização de desenvolvimento de produto. Inovação. Indústria automobilística. Países emergentes.

\section{Introdução}

A divisão internacional do trabalho em atividades de inovação, e mais especificamente em projeto de produto, tem sido objeto de intensa reflexão e discussão tanto do ponto de vista das empresas e de suas práticas gerenciais (HARVEY; GRIFFITH, 2007; MUDAMBI et al., 2007; McDONOUGH et al., 2001; CHIESA, 2000; McDONOUGH et al., 1999; GASSMANN; VON ZEDTWITZ, 1999; MEDCOF, 1997), quanto do ponto de vista das políticas públicas objetivando incrementar a capacidade de inovação em empresas locais (subsidiárias de multinacionais ou não) com vistas ao desenvolvimento sócio-econômico dos países (SALERNO et al., 2003, 2004; BRASIL, 2008). Tais discussões ganharam mais corpo com a chamada globalização, nos anos 1990, e com políticas de inovação levadas a cabo pelas empresas multinacionais, ou transnacionais (doravante denominadas TNCs), que passaram a cogitar o desenvolvimento de "produtos globais", aqui definidos como produtos destinados à produção e/ou comercialização simultânea em diferentes e numerosos países. Em alguns casos, a adoção de tal política conduziu à (re)centralização de tais atividades nas matrizes ou centros de desenvolvimento localizados em países desenvolvidos, eliminando ou reduzindo drasticamente a participação das demais unidades nessas atividades (FLEURY; FLEURY, 2006). Em outros, as empresas reorganizaram as atividades de inovação de modo a inserir algumas subsidiárias no processo de desenvolvimento de produtos, seguindo o princípio de que empresas transnacionais poderiam, e deveriam, considerar as competências ou vantagens comparativas apresentadas por cada unidade e combiná-las em uma estrutura em forma de rede, na qual as atividades seriam distribuídas às unidades conforme suas características (BARTLETT; GHOSHAL, 1992).

A literatura sobre a internacionalização das atividades de inovação em TNCs apresenta duas razões fundamentais para a descentralização de atividades dos centros de desenvolvimento ligados às matrizes em direção às subsidiárias: primeiro, razões relativas ao mercado - inserir as subsidiárias nas redes de inovação e/ou disponibilizar atividades de inovação próximas aos mercados das subsidiárias permitiria captar melhor as preferências locais, possibilitando ampliar a penetração dos produtos nesses mercados; segundo, razões ligadas à tecnologia - quando tecnologias não dominadas pelo centro de desenvolvimento principal estão disponíveis em outros países; nesse caso, as empresas inaugurariam estruturas de inovação em 
suas subsidiárias a fim de ter acesso a tal conhecimento (VON ZEDTWITZ; GASSMANN, 2002; CHIESA, 2000; GASSMANN; VON ZEDTWITZ, 1999; FLORIDA, 1997; REDDY, 1997; DUNNING, 1994). Contudo, tais razões não são suficientes para explicar algumas situações, observáveis empiricamente, de internacionalização das atividades de inovação. Por exemplo, em um mesmo setor econômico, diferentes empresas aparentam adotar diferentes posturas quanto à questão da descentralização de atividades de inovação, ainda que todas operem em um mesmo mercado. Além disso, algumas subsidiárias em determinados países realizam mais atividades, aprofundando suas competências em inovação, do que outras. Finalmente, a tecnologia não dominada pela matriz e disponível no país da subsidiária poderia ser transferida para o centro de desenvolvimento; de fato, há casos em que tal ocorre, porém há casos em que a matriz prefere manter na subsidiária as atividades relativas àquela tecnologia.

Nos estudos analisados, a questão da determinação de qual e como será a divisão do trabalho relacionado às atividades de $\mathrm{P}, \mathrm{D} \& \mathrm{E}$ entre matrizes e subsidiárias de empresas TNCs tem sido abordada considerando-se somente a visão das matrizes a esse respeito. $\mathrm{O}$ pressuposto é que tal determinação é sempre realizada pelas matrizes, o que, formalmente, é verdadeiro, pois é prerrogativa da cúpula das corporações o delineamento das estratégias da organização, a administração da relação entre a empresa e seu ambiente e a alocação de recursos entre as várias divisões (MINTZBERG, 1983; DRUCKER, 1998), tarefas essas que impactam, de forma evidente e marcante, as decisões sobre as atividades de inovação que as divisões levarão a cabo. Contudo, ainda que a palavra final seja da cúpula, isto é, dos escritórios centrais das TNCs, o processo de decisão acerca da divisão internacional do trabalho em atividades de $\mathrm{P}, \mathrm{D} \& \mathrm{E}$ pode não ser somente top-down; estratégias elaboradas pelas subsidiárias podem fazer parte do processo, modificando, eventualmente, as estratégias definidas pela cúpula da corporação, num processo emergente de elaboração de estratégias (MINTZBERG, 1994; 1987). Na realidade, sendo as atividades de inovação consideradas estratégicas do ponto de vista da sobrevivência a longo prazo da subsidiária, é do seu interesse atraí-las para si, além das atividades de distribuição ou produção que ela porventura realize. Nesse sentido, as subsidiárias teriam um papel relevante e ativo no processo de definição da divisão internacional do trabalho de inovação.

O objetivo desse artigo é, a partir do caso do setor automotivo brasileiro, discutir as lógicas seguidas por empresas transnacionais ao estabelecerem atividades de inovação, mais especificamente atividades de desenvolvimento de produtos globais, em países que não os de origem, elucidando o papel das subsidiárias na construção de tais lógicas. O setor automotivo é particularmente relevante para tal estudo, uma vez que seu produto é complexo do ponto de vista do projeto e da produção, é constituído de empresas com unidades em diversos países e é difusor de "ondas organizacionais" como engenharia simultânea, produto mundial, codesign, normas de controle de qualidade em projeto.

Propomos que as decisões sobre essa divisão internacional de trabalho são influenciadas também por outros fatores: 1) aspectos relacionados à estratégia competitiva do produto a ser lançado, em particular, o tempo de desenvolvimento e sua importância relativa dentro do segmento de mercado ao qual o produto se destina; 2) por restrições ou oportunidades advindas da natureza das atividades de desenvolvimento de produtos, das limitações de capacidade físicas (homenshora e/ou disponibilidade de equipamentos e sistemas de engenharia) para tratar de vários projetos simultaneamente, $\mathrm{e}$ das próprias características do processo de desenvolvimento de produtos, quando a subsidiária, ainda que não possua nenhuma competência tecnológica distinta em relação à matriz, possui competências de gestão - flexibilidade, propostas de solução rápidas e com menor custo, considerado como custo do projeto e desenvolvimento, não o custo hora do pessoal; 3) características de relacionamento entre matrizes e subsidiárias, em especial as relações de poder entre elas.

A fim de investigar tais proposições, foram realizados três estudos de caso em montadoras de veículos, nas quais foram feitos levantamentos e entrevistas nas matrizes e nas subsidiárias no Brasil; casos de controle foram desenvolvidos posteriormente também em três outras montadoras e três autopeças. As montadoras estudadas estão entre as mais relevantes do setor, congregando a maior parte do mercado e das atividades de desenvolvimento de produtos no Brasil; as autopeças foram escolhidas pela sua participação em atividades de $\mathrm{P}, \mathrm{D} \& \mathrm{E}$ ao lado das montadoras.

\section{Revisão conceitual e proposições}

As atividades de inovação influenciam diretamente o desempenho da empresa, donde a necessidade de racionalizar sua organização e seu gerenciamento, a exemplo do que tem sido realizado há mais tempo, com a produção strictu sensu. Contudo, as atividades de P, D \& E possuem diferenças em relação às atividades de produção: são em sua maioria abstratas, não repetitivas, cercadas de incertezas, sofrendo forte influência de variáveis exógenas ao processo e lidam com fluxos de caixa negativos, características opostas àquelas observadas nas atividades de operação (CLARK; FUJIMOTO, 1991; GIARD; MIDLER, 1993).

\subsection{Internacionalização do desenvolvimento de produtos globais}

A discussão em torno dos benefícios ou não da internacionalização das atividades de inovação em TNCs intensificou-se nos anos 1990 a reboque da globalização 
das atividades de produção e das tendências de divisão internacional do trabalho que se seguiram. A globalização a princípio pareceu apontar para a tendência de homogeneização de preferências dos consumidores, dando margem ao conceito de "produto global" (LEVITT, 1983), que poderia significar tanto a centralização do desenvolvimento de produtos, uma vez que o mesmo produto seria comercializado nos diversos mercados, quanto a dispersão da pesquisa e desenvolvimento em uma configuração de "rede", na qual cada unidade contribuiria com uma competência específica para a concepção de um mesmo produto, conforme o conceito de empresa transnacional proposto por Bartlett e Ghoshal (1992). Enquanto a primeira possibilidade traria como vantagem economias de escala, a segunda poderia se beneficiar de bolsões tecnológicos, colaborando para o incremento do desempenho do produto final. Contudo, o pressuposto de homogeneização dos mercados não se concretizou completamente (BRUCE et al., 2007). Disparidades permaneceram, forçando as empresas a criarem ou adaptarem produtos para mercados específicos e introduzindo novas possibilidades de divisão internacional do trabalho. Uma alternativa adotada pelas empresas como forma de manter o conceito de produto "global" e algumas de suas vantagens é a de conceber uma "plataforma" de produto comum a vários mercados, adaptando atributos sobre tal "plataforma" de modo a diferenciar os produtos nos mercados finais (MUFFATTO, 1999; ROBERTSON; ULRICH, 1998).

Os benefícios e problemas da adoção do conceito de produto global e da redistribuição das atividades de inovação foram analisados tanto do ponto de vista das empresas e cadeias produtivas que se submetiam ao processo, quanto do ponto de vista das nações afetadas por tal divisão do trabalho. Por exemplo, indagou-se a respeito da migração de atividades de inovação de países emergentes para os países centrais e as consequências de tal situação para o desenvolvimento dos primeiros (FLEURY; FLEURY, 2006; SALERNO et al., 2004; CONSONI, 2004; FLEURY, 1999). Para as empresas, a internacionalização de P, D \& E traria como vantagens fundamentais a maior integração com os mercados aos quais os produtos se destinam e a possibilidade de aproveitamento de competências tecnológicas externas aos países centrais (technological sourcing). De fato, a proximidade dos mercados e a busca por novas tecnologias podem ser a própria razão da existência de uma subsidiária (FERDOWS, 1997; DUNNING, 1993). Assim, a literatura categoriza as razões para a dispersão de atividades de inovação conforme esses dois grandes direcionadores, o mercado e a tecnologia. Do lado da tecnologia, enquadram-se: a proximidade com universidades e centros de pesquisa; o acesso a especialistas locais; o acesso a competências desenvolvidas historicamente nas próprias subsidiárias; aspectos referentes à emissão e ao depósito de patentes locais; diluição de riscos entre diferentes unidades de pesquisa; existência de subsídios e outros incentivos à P, D \& E. Do lado do mercado, estão: a necessidade de adequação a requisitos locais; de assistência técnica aos consumidores; a melhoria ou manutenção da imagem da empresa junto aos consumidores locais; a possibilidade de lançamento simultâneo de produtos. Há ainda alguns fatores não direcionados pela tecnologia ou pelos mercados como: possíveis reduções de custos devidas a vantagens locais específicas (tipicamente, menores custos de mão de obra); a possibilidade de aproveitar as diferenças de fuso horário a fim de agilizar o processo de pesquisa e desenvolvimento de produtos; e a necessidade de suporte a atividades de produção locais (VON ZEDTWITZ; GASSMANN, 2002; MIOTTI; SACHWALD, 2001; CHIESA, 2000; REDDY, 1997; FLORIDA, 1997).

Por sua vez, os problemas oriundos da descentralização de P, D \& E dizem respeito aos custos advindos da replicação de estruturas de inovação e das dificuldades de comunicação e coordenação de equipes de pesquisa e desenvolvimento fisicamente distantes. Não obstante o desenvolvimento de novas tecnologias de informação e comunicação, que poderiam facilitar a dispersão de P, D \& E entre diferentes unidades (REDDY, 1997), as atividades de inovação possuem um forte componente tácito, relacionado à sua própria natureza de atividade abstrata, o que faz com que boa parte da comunicação deva ocorrer presencialmente. Também, atividades de P, D \& E dispersas correm maior risco de quebra de sigilo.

\subsection{Divisão internacional do trabalho de concepção e a dimensão competitiva "tempo de desenvolvimento"}

O desenvolvimento de produtos ocorre fundamentado na crença, ou na aposta, de que provavelmente o mercado reagirá de modo favorável a esta ou àquela especificação. Ao mesmo tempo, as escolhas realizadas e os riscos assumidos durante o período de projeto impactam o desempenho da firma durante toda a vida do produto. O interesse das empresas é, naturalmente, diminuir ao máximo as incertezas e os riscos que cercam um projeto.

Duas das formas de se reduzir os riscos relacionados à atividade de desenvolvimento de produtos são: melhorar o conhecimento acerca do mercado presente e, principalmente, da dinâmica do mercado ao qual o produto se dirige; e reduzir o tempo de desenvolvimento. Como o desenvolvimento de produtos é uma atividade abstrata realizada sobre um objeto virtual em transformação (VELTZ, 2000) sobre o qual se definem algumas informações prévias, coletadas junto ao mercado (dinâmico) ao qual o objeto (produto) se dirige, quanto mais rápido for o desenvolvimento, mais tais informações continuarão a ser pertinentes, e o risco de rejeição do produto junto ao mercado será menor. Além disso, em ambientes nos quais a competição se dá por inovação ou por introdução de novos produtos, 
é evidente que a rapidez no desenvolvimento é um fator preponderante, podendo conduzir inclusive a vantagens de "primeiro entrante" - a competição ocorre baseada no tempo (STALK, 1997). A importância do tempo é, portanto, modulada pela situação concorrencial na qual a empresa se encontra, e o tempo de projeto pode ser uma variável estratégica (MIDLER, 1993).

Para melhorar a performance do desenvolvimento de produtos, dada a natureza dessa atividade, seria necessário admitir a existência de imprevistos e erros de previsão que conduzam a possíveis modificações e, a partir daí, construir uma capacidade de detecção de problemas e reação rápida e pouco custosa (VERGANTI, 1999; MIDLER, 1993). Dessa forma, para minimizar o tempo de desenvolvimento seria preciso estabelecer um equilíbrio entre as capacidades de antecipação e reação durante o projeto; isto é, de um lado, as equipes devem estar aptas a analisar, o mais cedo possível, os impactos de suas escolhas com relação aos requisitos mercadológicos, facilidade de manufatura do projeto, confiabilidade etc; de outro, elas devem ser capazes de reagir rapidamente a dados novos, surgidos durante o processo de desenvolvimento, modificando o projeto - em outras palavras, é necessário que o processo de desenvolvimento seja flexível, no sentido de lidar com imprevistos, alterações.

Dentre as possibilidades de ampliar a capacidade de antecipação e reação durante o projeto estariam (VERGANTI, 1999): a adoção de recursos flexíveis (capacitação dos projetistas, prototipagem rápida, CAD/CAM integrados); a superposição de etapas do desenvolvimento (engenharia simultânea); a manutenção de redundâncias na estrutura de desenvolvimento; a adoção de "soluções flexíveis", como projeto modular; a construção da capacidade de aprendizagem sobre o produto por meio da experiência relativa a projetos anteriores similares; o uso sistemático de equipes de trabalho multidisciplinares, colocação dos membros das equipes, e incremento da comunicação, envolvendo desde o início do projeto os seus principais atores e fazendo com que eles compartilhem objetivos (sendo avaliados, por exemplo, por indicadores comuns), entre outros.

Notamos, portanto, que a estrutura organizacional e a forma de gestão das atividades de P, D \& E na empresa podem afetar o tempo de processo de desenvolvimento. De fato, muito da literatura sobre organização e gestão dessas atividades desenvolveu-se a partir da necessidade de reduzir o tempo de desenvolvimento do produto, desde a concepção inicial até a sua disponibilização no mercado - originando conceitos como "engenharia simultânea", "codesign" (projeto conjunto com fornecedores), "gerentes de projeto pesopesado", entre outros, que pretendem justamente incrementar a coordenação entre as diversas atividades do processo de desenvolvimento (WOMACK et al., 1990; CLARK;
FUJIMOTO, 1991; CLARK; WHEELWRIGHT, 1993; CUSUMANO; NOBEOKA, 1999).

Para o caso particular da estrutura organizacional global de atividades de P, D \& E, não há consenso, na literatura, acerca do efeito de algumas práticas na redução no tempo de desenvolvimento: por exemplo, a redução de tempo apontada como um benefício proporcionado pela centralização dessas atividades em uma mesma equipe, em um mesmo local; a dispersão de $\mathrm{P}, \mathrm{D}$ \& $\mathrm{E}$ entre diferentes unidades levaria a problemas de comunicação entre os membros da equipe, dada a natureza abstrata das atividades de concepção e a consequente abundância de comunicação tácita; tais problemas incrementariam o tempo de desenvolvimento de produtos (VON ZEDWITZ; GASSMANN, 2002). Já Harley e Griffith (2007) argumentam que seria possível o uso de equipes "virtuais" de desenvolvimento e lançamento de produtos ou de equipes geograficamente dispersas e conectadas telematicamente, as quais poderiam contribuir para a criação de vantagens competitivas relacionadas ao tempo de lançamento de novos produtos globais. $\mathrm{Na}$ pesquisa de campo tal não foi verificado.

A inexistência de consenso a esse respeito sugere que a relação entre tempo de desenvolvimento e organização (centralização $\times$ descentralização) do processo de desenvolvimento de produtos pode ser mediada por outras variáveis. Uma variável possível é o grau de adaptação do produto global às condições locais. Supondo que o produto a ser desenvolvido seja um produto global na acepção original do termo (isto é, o produto será comercializado sem adaptações nos diversos mercados), a centralização do desenvolvimento pode ser vantajosa do ponto de vista do tempo de desenvolvimento e economia de recursos. Porém, se o produto "global" sofrer adaptações (sobre uma plataforma comum) considerando os diversos mercados, a centralização, embora continue a ser vantajosa do ponto de vista da economia de recursos, pode se tornar problemática para a redução do tempo de desenvolvimento. Isso ocorreria porque, conforme o número de adaptações ou novos atributos a serem desenvolvidos sobre a plataforma, o volume de trabalho do escritório de projetos central aumentaria, criando-se uma "fila" de projetos à espera de tratamento. Essa "fila" poderia ser reduzida com a ampliação do centro de desenvolvimento; outra alternativa seria ampliar a estrutura de P, D \& E, replicando-a em direção a outras unidades. Esta última opção resolveria também o problema da sensibilidade dos projetistas com relação às adaptações aos mercados locais: caso os atributos a serem modificados dependam de conhecimento tácito, não há possibilidade de transferir as informações coletadas pelos escritórios locais à unidade de projeto central. Assim, a alternativa seria designar tais adaptações a projetistas das unidades às quais os produtos se destinam.

Dessa discussão, emergem duas proposições a serem investigadas: 
- Proposição 1: o desenvolvimento de produtos globais será descentralizado em direção às subsidiárias para os produtos que (1a) sofrem mais adaptações relativas às condições locais e que (1b) necessitem de uma vantagem competitiva relativa ao tempo de desenvolvimento.

- Proposição 2: o desenvolvimento de produtos globais será descentralizado em direção às subsidiárias caso o conhecimento da subsidiária não possa ser transferido para a matriz, seja por motivos de custo, competência ou outros.

A partir da primeira proposição, nota-se que processos de desenvolvimento relativos a produtos diferentes deverão ser organizados de maneiras diferentes. Isso porque, conforme o segmento de mercado ao qual o produto se destina, podem ser necessárias mais ou menos modificações sobre a plataforma comum; além disso, a variável competitiva "tempo de desenvolvimento" pode ter importância desigual em ambientes competitivos diferentes. Portanto, em uma empresa que produza e comercialize diversos produtos, podem ser encontradas estruturas de desenvolvimento de produtos mais descentralizadas para alguns segmentos e mais centralizadas para outros segmentos.

\subsection{O papel das subsidiárias: para além da passividade}

Os estudos acerca de estruturas para projeto global (por exemplo, GASSMANN; VON ZEDTWITZ, 2001; CHIESA, 2000) usualmente tratam o processo de definição da divisão internacional do trabalho de maneira top-down, ou seja, os fatores que promovem a dispersão ou a concentração de atividades de inovação em TNCs seriam analisados pela cúpula estratégica da corporação vis-à-vis as características de cada subsidiária, sendo então definida a configuração organizacional para P, D \& E; as subsidiárias são consideradas unidades passivas nesse processo. Porém, se um dos fatores que induzem a dispersão de atividades de inovação é a possibilidade de aproveitar competências tecnológicas historicamente desenvolvidas nas subsidiárias, é de se perguntar como tais competências foram desenvolvidas: se a matriz assim o decidiu, então são outros os fatores preponderantes para a dispersão das atividades de P, D \& E; caso as competências tenham sido desenvolvidas de forma puramente endógena, então algum outro fator explicativo, não elencado anteriormente, deve estar presente.

Gammelgaard (1999) afirma que uma subsidiária pode incrementar suas competências por meio de certo grau de autonomia, que, para o autor, reflete as ambições dos gerentes locais, que possuem poder formal ou informal na organização. Mudambi et al. (2007) também demonstram que a maior autonomia da subsidiária correlaciona-se positivamente com a geração de conhecimento em P, D \& E na filial. Contudo, em ambos os trabalhos, não é explicado o processo de obtenção dessa autonomia para desenvolver atividades de inovação.

Por sua vez, Birkinshaw e Hood (1998) apontam a existência de três mecanismos responsáveis pela designação dos papéis das subsidiárias em relação à corporação. Primeiro, a designação da matriz; segundo, a escolha da subsidiária, ou seja, ela mesma define o papel que deseja possuir; terceiro, o ambiente local, isto é, o papel da subsidiária seria também em função das restrições e oportunidades do mercado local. As filiais são vistas, portanto, como entidades semiautônomas, capazes de tomar suas próprias decisões, que podem ser restritas, contudo, por exigências da matriz e por características do mercado local. Pela combinação dos três mecanismos de designação dos papéis, a filial pode desenvolver suas capacidades e ganhar responsabilidade por algum negócio da corporação.

Os autores definem três tipos de fatores que influenciam a predominância de um ou mais dos três mecanismos de designação e consequente evolução (ou atrofia) das capacitações das subsidiárias: (1) fatores relacionados ao contexto da corporação: existência de mecanismos de estímulo à competição entre as unidades pela responsabilidade por algum negócio, legitimando assim o processo pelo qual a filial pode ganhar ou perder responsabilidades; nível de descentralização do processo de tomada de decisão, ou seja, a autonomia concedida às subsidiárias; atitudes da matriz com relação à subsidiária, em especial a existência de etnocentrismo por parte da direção da matriz; (2) fatores relacionados ao contexto da subsidiária: desempenho econômico da filial; qualidade das relações matrizsubsidiária, isto é, os laços informais entre os tomadores de decisão da matriz e os diretores da subsidiária - um bom relacionamento tende a atrair investimentos para a filial, se ela assim o desejar; orientação "empreendedora" dos funcionários da filial, isto é, a predisposição dos funcionários a perceberem e responderem rapidamente a novas oportunidades; (3) fatores relacionados ao país no qual a subsidiária se encontra: dinamismo do ambiente local em relação à demanda, setores de apoio, condições de concorrência - ambientes mais dinâmicos proporcionariam estímulos para incrementar a capacitação; apoio do governo local, na forma de incentivos diretos ou indiretos; importância estratégica do país para a corporação.

A presença desses fatores faria com que a filial participasse mais ou menos ativamente do processo de evolução de suas capacitações. Por exemplo, uma unidade com bom desempenho econômico tende a atrair mais investimento e, ao mesmo tempo, pode ter mais legitimidade para decidir sobre seus próprios rumos quanto ao seu papel na corporação. Por outro lado, se existe etnocentrismo, a participação da filial nas atividades de P, D \& E tende a ser menor. Tal abordagem permite explicar as diferenças na forma de divisão internacional do trabalho entre TNCs 
atuando num mesmo país e em um mesmo setor econômico (o que significa oportunidades e características de mercado e de competências tecnológicas externas idênticas para todas): as atitudes das próprias subsidiárias podem variar entre as empresas. Essa perspectiva é coerente com a abordagem de estratégia emergente apresentada por Mintzberg (1994, 1987) e Prahalad e Hamel (1990): as estratégias não seriam somente elaboradas pela cúpula estratégica (a matriz), de forma deliberada, mas poderiam emergir a partir de outras partes da corporação, fundamentadas em ações que respondem de forma $a d$ hoc às situações e que podem criar competências importantes. Deste modo, embora a estratégia da matriz possa se centralizar em $\mathrm{P}$, D \& E, a experiência bem sucedida da engenharia local em desenvolver novos produtos a partir dos desenvolvidos na matriz e a despeito da orientação estratégica inicial poderia conduzir a uma mudança de estratégia da corporação, que passa a formalmente considerar a subsidiária em questão um centro de competências. É evidente que, para que a estrutura local possa decidir investir em uma estratégia diferente da matriz, deve possuir recursos próprios e certo grau de poder frente à corporação. Nesse caso, o poder da subsidiária poderia advir, dentre outras fontes: de seu bom desempenho econômico; das boas relações pessoais entre os responsáveis pela subsidiária e/ou pelas atividades de inovação locais e os dirigentes da matriz; da importância estratégica do mercado potencial ao qual a subsidiária tem acesso privilegiado; das informações, relativas a esse mercado estratégico, às quais a subsidiária tem acesso privilegiado (MORGAN, 1998; BERNOUX, 1990).

Caberia, entretanto, verificar se tal perspectiva pode ser aplicada a subsidiárias localizadas em países emergentes: nessas empresas, fatores como relacionamento matrizsubsidiária seriam significativos a ponto de influenciar a divisão internacional do trabalho de inovação de maneira a favorecer a subsidiária? Assim, a investigação a respeito das diferentes formas de internacionalização das atividades de inovação em direção a subsidiárias completar-se-ia com a terceira proposição, a respeito do papel das subsidiárias no processo de divisão do trabalho:

- Proposição 3: Dada a proposição 1, a subsidiária pode atrair atividades de P, D \& E para si, conforme as relações entre ela e sua matriz. Quanto maior o poder da subsidiária dentro do grupo, maior a possibilidade do desenvolvimento de produtos globais ser descentralizado em direção a ela.

\section{Metodologia da investigação de campo}

A fim de investigar as proposições colocadas acima, optou-se pela realização de estudos de caso, uma vez que se trata de questões contemporâneas, dentro de um contexto que não pode ser separado do objeto de estudo (YIN, 1994). Além disso, a decisão de analisar o processo de internacionalização de P, D \& E de forma dinâmica conduziu à adoção de métodos qualitativos de pesquisa (BRYMAN, 1989).

Foram realizados estudos de caso em 9 empresas do setor automotivo, sendo 6 montadoras (que envolvem quase o universo de projeto local de veículos) e 3 autopeças, fundamentados em entrevistas semiestruturadas, com o apoio de fontes documentais. Definimos 2 grupos de casos: os principais, nos quais as proposições iniciais foram testadas e aprofundadas (3 montadoras); e os casos de controle, nos quais as formulações e conclusões oriundas dos casos principais foram validadas ( 3 montadoras e três autopeças). As atividades realizadas para cada empresa estão sintetizadas na Tabela 1. A fim de reduzir problemas de distorção nas informações coletadas e seguindo orientações de Eisenhardt (1989) e de Voss et al. (2005), realizaram-se entrevistas com executivos de diferentes níveis hierárquicos dentro de uma mesma empresa - diretores e gerentes de engenharia de produto, engenheiros e técnicos - bem como representantes sindicais ligados à área de desenvolvimento de produtos. Em alguns casos também entrevistamos profissionais das áreas de compras e marketing. Nas montadoras de veículos, foram entrevistados profissionais das matrizes e das respectivas subsidiárias brasileiras, a fim de confrontar as opiniões. Nas 3 montadoras analisadas em profundidade, focalizamos a participação da subsidiária nas atividades de desenvolvimento de um produto (ou família) que estivesse sendo desenvolvido ou de desenvolvimento recente (idade inferior a 5 anos no momento da pesquisa) e que fosse destinado ao segmento "de entrada", isto é, veículos de menor preço - compactos/subcompactos, que, em tese, teriam um mercado maior em países emergentes. Em todos os casos, foram realizadas perguntas a respeito da participação brasileira em um produto diferente desse, destinado a uma faixa de preço mais elevado, de forma a comparar a participação da subsidiária em produtos com diferentes estratégias de mercado.

A escolha de quais empresas pesquisar levou em consideração o nível de atividades de desenvolvimento de produtos globais realizadas localmente pelas empresas, a partir de evidências empíricas provenientes de pesquisas que realizamos previamente, e de sondagens com profissionais do setor. No caso das 3 montadoras analisadas em profundidade, duas delas, operando no Brasil há mais de 25 anos no momento da pesquisa, demonstravam possuir alto nível de atividades de P, D \& E locais; a terceira era uma "nova entrante", fazendo parte da recente onda de investimentos de montadoras no País.

Seis empresas foram utilizadas como casos de controle, para verificação da justeza dos levantamentos e das conclusões. Enquadram-se nesse caso três montadoras, nas quais foram feitos levantamentos menos profundos (número menor de entrevistas). Com relação às empresas de autopeças, foram também enviados e obtidos 16 
questionários de fornecedores diretos das montadoras (first tiers) no Brasil, envolvendo temas sobre as atividades locais de $\mathrm{P}, \mathrm{D} \& \mathrm{E}$ e sobre que medidas poderiam levar ao aumento dessas atividades. Dessas 16, realizamos entrevistas pessoais de aprofundamento em três delas, consideradas como das gigantes do setor, envolvendo diretores de P, D \& E. As entrevistas nas autopeças foram fundamentais para confirmar as informações obtidas junto às montadoras, pois realizam projetos em codesign com suas clientes. Como a análise priorizou as montadoras, discutiremos em detalhes os casos dessas empresas, utilizando as informações obtidas nas autopeças para confronto de dados.

As fontes documentais consultadas foram outras pesquisas, notícias da imprensa especializada, de associações de classe e sindicatos, tais como a Associação Nacional dos Fabricantes de Veículos Automotores - ANFAVEA, e a Associação Mundial dos Fabricantes, o Sindicato Nacional das Empresas de Autopeças - Sindipeças, a Sociedade de Engenharia Automotiva (SAE), as revistas Autodata (Brasil), Automotive News (EUA) e os jornais Valor Econômico (Brasil) e Financial Times, além de busca em textos e informes disponíveis no site da rede de pesquisa sobre indústria automobilística Gerpisa.

\section{Estudos de caso}

A Montadora A está presente no Brasil há mais de 25 anos, ocupando, durante todo esse período, lugar de destaque

Tabela 1. Empresas pesquisadas.

\begin{tabular}{cc}
\hline Casos principais & Atividades \\
\hline Montadora A & $1,2,4,5,6,7,8,9,10,11,13$ \\
Montadora B & $1,2,4,5,6,7,8,9,10,11$ \\
Montadora C & $1,2,3,4,6,8,9,10,11$ \\
& Casos de controle \\
Montadora D & $2,4,5,6,7,9,10,11$ \\
Montadora E & $1,2,4,5,6,7,9,10,11,13$ \\
Montadora F & $2,4,5,6,7,9,10,11,13$ \\
Autopeças 1 & $2,4,5,7,10,11,12$ \\
Autopeças 2 & $2,4,5,7,10,11,12$ \\
Autopeças 3 & $2,6,7,8,10,11,12$ \\
\hline
\end{tabular}

Fonte: Elaboração dos autores.

Legendas: 1. Entrevistas no centro principal de P, D \& E (matriz, país-sede ou outro). 2. Entrevistas nas unidades de P, D \& E brasileiras. 3. Entrevista com membros da alta cúpula na matriz. 4. Entrevista com membros da alta cúpula brasileira. 5. Entrevista com gerentes de P, D \& E no Brasil. 6. Entrevistas com staff da diretoria brasileira. 7. Entrevista com profissionais de P, D \& E no Brasil. 8. Entrevista com profissionais de P, D \& E no centro principal (matriz, país-sede ou outro). 9. Entrevistas com fornecedores first-tier que realizam co-design. 10. Discussão com pesquisadores brasileiros e/ou estrangeiros. 11. Participação em eventos profissionais nos quais o caso em questão foi discutido. 12. Questionário enviado por e-mail ou correio.13. Entrevistas com representantes sindicais. no mercado local de veículos de passeio. Desde o início de suas operações, optou por realizar localmente certas atividades de desenvolvimento de produtos, que resultaram, ao longo do tempo, na construção de competências técnicas e gerenciais para projeto associadas à mão de obra local, bem como no estabelecimento de alguma estrutura física (laboratórios locais). No período de mercado fechado, tais competências geraram pelo menos 2 casos bem sucedidos de produtos que podem ser considerados "locais", ainda que desenvolvidos sobre bases, ou "plataformas", projetadas na matriz.

Após a abertura do mercado, foi detectada uma diminuição das atividades de engenharia dessa montadora no Brasil (QUADROS; QUEIROZ, 2000), com centralização na matriz. Tal estratégia parecia surpreendente por ocorrer em uma empresa que até então se destacava pela força de sua engenharia local, ainda mais porque, na mesma época, duas de suas concorrentes optavam pelo crescimento de suas engenharias brasileiras. No entanto, no início dos anos 2000 a Montadora A retomou as atividades de engenharia, participando do desenvolvimento de um novo modelo e de seu derivativo sedã, ambos os veículos de pequeno porte. O primeiro modelo foi desenvolvido na matriz, com a participação de profissionais brasileiros, e destinava-se aos mercados da Espanha, Eslováquia, Brasil e China. O derivativo, destinado inicialmente aos mercados do Brasil, da China e da África do Sul, foi desenvolvido sob a responsabilidade da engenharia brasileira. Isto significa que, durante as fases de concepção de produto, realizadas na matriz, houve a participação de profissionais brasileiros da engenharia, compras e qualidade; a engenharia de produto e de processo foi feita parcialmente no Brasil; o design também foi realizado pela equipe brasileira, e a subsidiária cuidou do gerenciamento do processo de desenvolvimento, objetivando cumprir metas de prazo e custo.

O Brasil foi escolhido como responsável pelo desenvolvimento por ser o mercado mais importante para o modelo sedã e devido à sua competência para desenvolvimento de produtos, demonstrada no período de mercado fechado. Tal foi confirmado em entrevistas com fornecedores que participaram de atividades de codesign com a montadora. A escolha também considerou o relacionamento com a matriz, o que é particularmente claro no caso do terceiro modelo estudado, um segundo derivativo compacto da plataforma do primeiro modelo. O desenvolvimento desse segundo derivativo foi proposto pela subsidiária brasileira a fim de suprir a necessidade de um novo produto da Montadora A no segmento de entrada, já que seu principal produto nesse segmento era um modelo bastante antigo, e sua principal concorrente no Brasil obtivera a liderança de mercado justamente devido ao desempenho nesse segmento. A filial brasileira enfrentou alguns conflitos antes de obter a aprovação da matriz para esse modelo; para a aprovação, após 2 anos de negociação, 
foi fundamental o fato de a unidade brasileira ser, dentro do grupo mundial, a segunda em termos de volume de produção e a terceira em vendas, e a subsidiária mais antiga do grupo. Esse derivativo foi totalmente desenvolvido no Brasil, e a atuação da matriz foi praticamente restrita à aprovação final dos desenhos, o que, conforme os entrevistados, ocorreu menos devido a uma suposta falta de competência local, e sim devido a uma tentativa de manutenção de poder por parte da matriz, uma vez que houve pouquíssimos vetos da matriz às propostas brasileiras.

$\mathrm{O}$ produto foi lançado ao término do levantamento de campo e alcançou sucesso no mercado local. A empresa passou a exportar o derivativo para outros países emergentes, mantendo sua produção no Brasil e, a seguir, lançou-o na Europa: um produto concebido com vistas ao mercado interno acabou por extrapolar sua vocação inicial. Além disso, há indícios de que a corporação pretende fazer da filial brasileira um "centro de competências" para o desenvolvimento de produtos destinados a mercados de países emergentes, agilizando a introdução de novos produtos nesses mercados e aliviando a carga da matriz.

A segunda montadora analisada, a Montadora B, inaugurou suas instalações após a Montadora A. Em seus primeiros anos de operação, ela ocupava o quarto lugar no mercado de veículos de passeio. Na década de 1990, aproveitando-se de maneira ágil dos recém-promovidos incentivos para veículos equipados com motores de até mil cilindradas, a empresa iniciou sua ascensão no mercado local até atingir a liderança. Tal período coincidiu com a consolidação das atividades de engenharia locais, após um período de "engenharia zero" e de engenharia para adaptação. Nos anos 2000, quando a matriz enfrentou uma séria crise financeira, a filial brasileira gerou sistematicamente bons resultados, o que terminou por aumentar a sua importância dentro do grupo.

A Montadora B integrou, nos anos 1990, a equipe de desenvolvimento de um produto concebido para produção e comercialização em países emergentes, tendo sido a responsável pelo gerenciamento do processo - ou seja, observar os custos e prazos a ele associados. As fases iniciais do processo de desenvolvimento foram centralizadas na matriz, com integração de profissionais brasileiros (da engenharia, de compras e qualidade); a partir da fase de engenharia de produto, toda a equipe envolvida foi enviada ao Brasil: não houve mais atividades de desenvolvimento na matriz. Dessa forma, a estrutura central pôde se dedicar a outros projetos, e, de acordo com nossos entrevistados, a focalização do desenvolvimento do veículo na filial brasileira terminou por agilizar sua introdução no mercado. O desenvolvimento dos derivativos desse modelo - pickup, sedã e station wagon - foi realizado pela subsidiária brasileira, excetuando-se algumas atividades de design e alguns testes. A partir de 2003 a estrutura de desenvolvimento de produtos da subsidiária foi reforçada pela construção de um Centro de Estilo local, permitindo a realização local do design dos modelos; também ocorreram investimentos de monta em alguns laboratórios - como uma câmara de interferência magnética, a única fora da matriz e a única dentre as filiais brasileiras de montadoras transnacionais. Segundo nossos entrevistados, não houve grandes conflitos com a matriz com relação a esses investimentos, o que pode ser justificado pelo poder possuído pela filial dentro da corporação.

A subsidiária brasileira é também formalmente considerada um "centro de competências" para desenvolvimento de motores a álcool e para desenvolvimento e teste de módulos de suspensão para outras unidades do grupo fora do Brasil. Todos os outros 4 "centros de competência" do grupo estão localizados no país-sede. O objetivo de tal descentralização, explicitado pelos entrevistados no Brasil e na matriz, é agilizar o desenvolvimento de produto.

As engenharias das empresas A e B têm maior participação no desenvolvimento de produtos destinados ao segmento de entrada. Há alguma participação no desenvolvimento de outros produtos, como os de "topo de linha", mas ela é menor, tanto em horas de engenharia quanto de responsabilidades, e ocorre na matriz. Os produtos de "topo de linha" sofrem menos adaptações - basicamente, devidas às diferentes condições de rodagem - do que os de "segmento de entrada", que são desenvolvidos com o Brasil como o (ou um dos) mercado(s) prioritário(s). Os veículos de "topo de linha", ao contrário, priorizam os mercados centrais.

A empresa $\mathrm{C}$ é a montadora, dentre as entrevistadas, que opera há menos tempo no Brasil; ela inaugurou sua planta brasileira na década de 1990. Dado que as atividades de desenvolvimento de produtos são associadas a riscos e a investimentos que só serão recuperados em longo prazo, é natural supor que a montadora tenha optado por não realizar tais atividades no Brasil, ao menos num primeiro momento, o que de fato ocorreu. As eventuais adaptações necessárias nos modelos produzidos localmente, dois deles do segmento de entrada, foram realizadas na matriz, em um Centro de Desenvolvimento no país-sede. Esse Centro foi também inaugurado nos anos 1990 com o objetivo de reduzir custos e tempo de desenvolvimento dos produtos globais, dentro da visão de concentrar as pessoas num único local, sem muitas "barreiras" físicas entre elas. No momento do projeto de novos veículos, a equipe da matriz, de uma forma bastante convencional, procura levar em conta as condições dos mercados locais, que lhes são transmitidas por meio de documentos elaborados por pequenas equipes de engenharia localizadas nas subsidiárias, cuja função é ser um "radar" das preferências, condições de uso e tendências dos mercados locais.

À medida que a montadora consolidava suas operações no Brasil, percebia que eram necessárias maiores adaptações em seus produtos, de modo a satisfazer as preferências e 
condições de uso e de renda do mercado local e também a ajustar o produto ao processo de fabricação brasileiro. Ao mesmo tempo, conforme nossos entrevistados, a empresa notou que, conforme o número de adaptações aumentava também o tempo de projeto aumentava, porque a capacidade física do Centro de Desenvolvimento não previa tal volume de trabalho. O mais alto responsável pelo desenvolvimento de produtos globais da empresa considerou que, na prática, a prioridade dada pelos gestores e engenheiros de projeto de produto era aos produtos mais sofisticados, com mais "apelo", voltados para os países centrais, e os projetos/ adaptações destinados a países emergentes sempre ficavam em segundo plano. Ainda segundo entrevistados, os bons resultados obtidos pela filial brasileira garantiram certo poder de influência para a unidade, que convenceu mais facilmente a matriz a respeito da necessidade de adaptações. Assim, para agilizar a introdução de novos produtos no mercado local, algumas adaptações passaram a ser realizadas localmente. Atualmente, a Montadora $\mathrm{C}$ prossegue com a consolidação da engenharia no Brasil, por meio da inauguração de alguns laboratórios (como de prototipagem e testes de materiais) e do envio de profissionais brasileiros para estágios no Centro de Desenvolvimento. De qualquer maneira, está num estágio muito abaixo das montadoras A e B.

A matriz da Montadora $\mathrm{C}$ promoveu nos últimos anos agressiva política de aquisições de outras empresas automotivas, algumas com engenharia própria de produtos. Hoje, conta com centros de desenvolvimento em vários países, inclusive no Leste Europeu, que desenvolve produtos para países emergentes, inclusive para o Brasil. Ou seja, o centro brasileiro é, ao menos até o momento, periférico, ao contrário do que ocorre com as empresas A e B.

Os casos de controle confirmaram as hipóteses. A empresa $\mathrm{D}$ é uma montadora que possui vários centros de desenvolvimento ao redor do mundo. No Brasil está localizado o principal centro fora dos países centrais, realizando projetos para países emergentes e também para produtos produzidos nos países europeus. A legitimidade do centro deve-se ao sucesso alcançado tanto pela subsidiária brasileira, quanto aos produtos lá desenvolvidos. À semelhança das empresas A e B, o centro foi recentemente expandido (alcançando cerca de 2000 funcionários e novos laboratórios e instrumentação no campo de prova), em parte devido ao posicionamento formal que ganhou no seio da corporação mundial, mas fundamentalmente após o governo brasileiro ter lançado política específica de incentivos para atividades de P, D \& E (Leis de Inovação, do Bem e linhas de financiamento).

A montadora $\mathrm{F}$, que atua no segmento de veículos comerciais (caminhões e ônibus) passou por um processo de centralização devido ao fracasso de um projeto local, teoricamente destinado ao mercado mundial - os entrevistados aqui atribuem o fracasso às hiperespecificações vindas da matriz, que tornou o produto muito caro e pouco atrativo. Consoante proposição 3, o relacionamento com a matriz ficou mais difícil. Mas a concorrência adotou estratégia de possibilitar a personalização de produtos conforme o uso previsto, o que, associado a uma política agressiva de preços, arrebatou boa parcela do mercado antes dominado pela $\mathrm{F}$. Isso mostra que o mercado deve ser visto numa perspectiva dinâmica, não só de tamanho, mas considerando também a concorrência: sem engenharia local é muito difícil fazer um caminhão taylor made (personalizado) conforme $\mathrm{o}$ produto, a rota etc.

Já a empresa E é um caso de controle peculiar. Lançou um produto e um negócio não existente na matriz que se mostrou altamente lucrativo. A matriz, então, decidiu incorporar para si a alta gestão do negócio, inclusive tentando centralizar o desenvolvimento de produtos. A matriz dá sugestões, parecendo, a princípio, atuar no desenvolvimento de produtos, mas na prática quase todas as horas de engenharia são centralizadas na subsidiária, uma vez que o codesign modular, extensivamente usado pela subsidiária, se faz localmente no Brasil. A subsidiária ganha autonomia, numa perspectiva pouco explorada pela literatura.

As empresas de autopeças 1, 2 e 3 possuem um comportamento semelhante. As 2 primeiras possuem forte engenharia de desenvolvimento de produto, sendo responsáveis por produtos inovadores no cenário mundial. Um alto gerente de P, D \& E da empresa 1 credita sua expansão à autonomia local de desenvolvimento. A subsidiária lançou produtos inéditos, ganhando mercado e projeção. Realiza várias atividades para a matriz. A empresa 3, em que pese seu gigantismo, é uma seguidora, e boa parte dos projetos acaba sendo realizada na matriz, o que a faz perder agilidade e qualidade - por exemplo, um de seus produtos, projetado para o sistema de suspensão da montadora D, foi subdimensionado para as condições de rodagem do Brasil e da América do Sul, precisando ser substituído às vésperas do lançamento do modelo. Isso pode ser creditado às mesmas características levantadas na montadora $\mathrm{C}$ : pouca prioridade dada pelo centro matriz a projetos para mercados emergentes, desconsideração das condições de uso do veículo, pouca disponibilidade para intercâmbio e trocas com a engenharia da subsidiária para absorver conhecimentos relativos ao mercado local. $\mathrm{O}$ exemplo confirma a proposição de descentralização para busca de agilidade.

\section{Discussão dos resultados}

Comparando-se os casos das Montadoras A, B e C, notamos que o envolvimento da filial brasileira nas atividades de inovação varia conforme os diferentes nichos de mercado, sendo maior para o segmento de entrada, que é o principal segmento no Brasil e no qual são necessárias 
mais adaptações. Para os demais segmentos, nos quais o Brasil não é um dos principais mercados, a participação da engenharia brasileira, no que se refere a desenvolvimento de produtos, é menor, e este tende a ocorrer na matriz.

Conforme os levantamentos, os principais motivos para integrar a engenharia local nos projetos são adequar o produto às condições e preferências locais (incluindo-se aqui a questão do barateamento do produto) e agilizar tais modificações. A adequação do produto às condições locais, embora seja afetada pelo grau de integração da engenharia brasileira no desenvolvimento, independe da descentralização do projeto em direção à filial, uma vez que o engenheiro brasileiro pode ser deslocado até o centro de projeto - levando consigo, evidentemente, as informações explícitas e tácitas a respeito das preferências do consumidor local e das condições de rodagem. É o que é realizado, por exemplo, no caso dos produtos "topo de linha". Já a agilidade nas modificações é tanto maior quanto maior for a autonomia das filiais e, logo, a descentralização de projeto, uma vez que tanto o projeto das modificações quanto a aprovação e implantação delas ficam sob a responsabilidade da filial. Mais: quanto mais modificações forem necessárias, maior será o impacto da descentralização no tempo do desenvolvimento. A maior necessidade de adaptações mina também a vantagem de economias de escala obtidas com a centralização do projeto de um produto padrão. Essas observações ficaram particularmente claras a partir do caso da empresa $\mathrm{C}$, que inicialmente adotou uma estratégia de centralização e padronização dos produtos para obter menor tempo de desenvolvimento, modificando tal estratégia à medida que maiores adaptações nos produtos foram sendo consideradas necessárias.

Portanto, a integração da engenharia local e a descentralização do desenvolvimento tendem a ser maiores no segmento de entrada por afetar positivamente critérios competitivos importantes para esse segmento, como preço (via redução de custos) e agilidade no desenvolvimento, devido à necessidade de mais adaptações nesse segmento. Para os demais segmentos, nos quais há menos necessidade de adaptações, a descentralização do desenvolvimento possui efeito, senão contrário, nulo; daí a opção pela centralização no desenvolvimento, ainda que com integração (comparativamente menor) da engenharia brasileira, que é deslocada para o centro de projeto. Assim, a primeira proposição pode ser considerada válida.

Nos casos das empresas A, B, C, D, E e F não encontramos competências tecnológicas distintas que expliquem a participação do Brasil no desenvolvimento de alguns produtos. Em compensação, encontramos uma grande experiência em identificar as necessidades de adaptações e projetá-las, em especial no que se refere às reduções de custo no produto final, sem que a imagem do produto junto ao mercado sofra muito. Essa seria uma habilidade tácita, difícil de ser transferida à matriz, conforme a proposição 2. Tome-se o caso da Montadora A, por exemplo, que destacou que uma das principais qualidades do engenheiro brasileiro é que ele "pensaria barato", ou seja, desde o início do projeto direciona seus esforços para a diminuição dos custos de projeto e dos custos do produto final, em termos de matérias-primas, por exemplo, ao contrário dos engenheiros da matriz, para quem o objetivo seria sempre a excelência tecnológica. Da mesma forma, a empresa $B$ afirma que seus engenheiros brasileiros sabem como desenvolver um carro barato sem transformá-lo em um carro com níveis mínimos de conforto e acabamento e totalmente desprovido de itens opcionais. O mesmo vale para a Montadora F (caso de controle). Ressalte-se que a experiência de engenharia somente pode ser adquirida ao longo da trajetória da unidade, alimentando um círculo virtuoso no qual a participação em projetos aumenta a experiência, que aumenta a participação em projetos; daí não ter sido um atributo citado pela empresa $\mathrm{C}$, cuja unidade brasileira é bastante nova, ao justificar a migração para uma estratégia de maior descentralização de engenharia.

A experiência em engenharia que as filiais brasileiras apresentam, contudo, teve um ponto de partida: ou a matriz delegou autonomia à filial, e esta optou por ampliar/capacitar sua engenharia, ou a matriz explicitamente designou que ela investisse na formação dessa capacitação. Nas duas situações, a matriz fez uma escolha pela filial brasileira; assim, é necessário que se explique por que tal opção foi realizada.

Além da experiência em engenharia, a mão de obra brasileira para projeto tem salários mais baixos do que a mão de obra das matrizes ou centros de projeto, localizadas nos países centrais. Essa característica é um fator importante para a descentralização, mas não pode ser apontada como fator primordial para a escolha do Brasil como participante em atividades de inovação ou sede de projeto - já que filiais localizadas em países como a China e a Índia também pagam salários menores do que os das matrizes.

Um atributo diferenciador das empresas A e B e no caso de controle $\mathrm{E}$ - as montadoras que apresentaram comparativamente maior nível de atividades de $\mathrm{P}, \mathrm{D} \& \mathrm{E}$ realizadas no Brasil, ao lado da empresa D - é o fato da filial ser o mercado mais importante entre os mercados emergentes. No caso da empresa D, a filial brasileira Figura entre as mais importantes e lucrativas da corporação, tendo inaugurado no final dos anos 1990 uma planta, fundamentada em produção modular, considerada das mais produtivas do setor no mundo. Ser o principal mercado leva a pelo menos 3 consequências: primeiro, o produto a ser desenvolvido tem como mercado-alvo principal o brasileiro; o mercado brasileiro será o primeiro a receber o produto; e as adaptações para os demais mercados serão realizadas sobre a "base" brasileira. Portanto, se a descentralização existir (pelas questões já mencionadas nos 
parágrafos anteriores), ela tende a ocorrer em direção ao Brasil. Em segundo lugar, sendo o mercado mais importante, o estabelecimento de uma estrutura de engenharia local envolve menos riscos do que em outros mercados, menos estratégicos, nos quais a permanência da filial não é tão garantida. Finalmente, a importância da filial dá a ela mais poder no momento da decisão sobre qual filial realizará atividades de desenvolvimento.

Essa última observação nos leva à proposição 3 , que afirma que a descentralização do desenvolvimento de produtos envolvendo uma determinada subsidiária dependerá do relacionamento entre essa filial e a matriz. De fato, ela foi confirmada, em especial nos casos das empresas A e B. A filial brasileira da Montadora B é a unidade estrangeira mais importante da corporação, e sua integração na estrutura de desenvolvimento de produtos da corporação é facilmente legitimada. O relacionamento da unidade brasileira da empresa A com sua matriz é mais conflituoso, porque a subsidiária tem uma trajetória que a qualifica a desenvolver produtos localmente - o que pode ser encarado como uma ameaça ao trabalho da matriz. A Montadora A apresentou-nos um caso em que as disputas pelo desenvolvimento de produtos são claras, e sua participação recente no desenvolvimento de produtos dependeu dos atributos que ela apresenta não só em termos de experiência em projeto, mas em importância de mercado e poder de negociação.

\section{Conclusões}

A análise dos resultados que obtivemos neste trabalho mostrou a emergência de 2 fatores importantes que afetam a determinação das estruturas de desenvolvimento de produtos globais: a busca pela diminuição do tempo de desenvolvimento de produtos e as relações de poder entre as unidades (matrizes, centro de projeto principal e subsidiárias).

A redução do tempo de desenvolvimento, sendo elemento comum aos casos investigados, pode indicar uma racionalidade seguida pelas empresas no momento da decisão sobre centralizar ou descentralizar as atividades de desenvolvimento de produto. A novidade não está na importância do tempo de desenvolvimento de produtos como componente de uma nova racionalidade para a organização e a gestão dos sistemas de produção, e sim no fato de que essa racionalidade está fortemente presente também quando se trata de organizar mundialmente as atividades de inovação. A procura pela diminuição do tempo de desenvolvimento possui resultados diferentes em termos de centralização ou descentralização das atividades de desenvolvimento de produtos conforme a maior ou menor possibilidade de padronização do produto em questão com relação aos diversos mercados aos quais se destina. Isso não significa, porém, que a redução de custos via economias de escala tenha sido abandonada como racionalidade; no caso automotivo, por exemplo, é possível realizar um compromisso entre escala/padronização e variedade com o uso de plataformas e derivativos.

O segundo elemento comum aos casos das empresas A, $\mathrm{B}$ e $\mathrm{C}$ e aos casos de controle $\mathrm{D}$ e $\mathrm{E}$, importante para definir se o desenvolvimento de produtos globais será mais ou menos descentralizado e quais subsidiárias serão envolvidas nessas atividades, é a relação de poder existente entre a matriz e as subsidiárias. A incorporação desse elemento na análise mostrou-nos que as subsidiárias não são passivas no processo de definição da divisão internacional do trabalho em atividades de inovação; ao contrário, elas procuram atrair para si tais atividades - aumentando a capacitação de seus funcionários, procurando realizar parcerias com institutos de pesquisa locais, buscando financiamentos locais para tais atividades (incluindo compra de equipamentos e instalação de laboratórios). O estudo das subsidiárias, em especial as localizadas em países em desenvolvimento, como agentes da descentralização ainda é incipiente na literatura. As subsidiárias são vistas, em geral, como "portas de entrada" que dão acesso a um mercado ou a uma tecnologia e, por isso, são inseridas na estrutura de P, D \& E. Por certo, as decisões finais são tomadas pela matriz, entretanto a pesquisa mostrou que o relacionamento entre matriz e filial influencia tal decisão: a matriz pode transferir certas atividades de desenvolvimento à filial por reconhecer a importância da filial (casos B, D e E) ou por reconhecer as razões da filial que demanda tal transferência (caso C e mesmo A).

Essa perspectiva é importante e merece ser ressaltada porque pode aumentar as possibilidades de inserção das filiais nas atividades de inovação. No caso do setor automotivo brasileiro, no qual as empresas que lideram as atividades de desenvolvimento de produtos globais são TNCs, isso pode significar que o aumento das atividades locais de desenvolvimento de produtos - com consequências em termos de transferência de tecnologia e aumento da capacitação tecnológica local para todo o setor - não depende somente da vontade das matrizes, mas pode ser estimulado por ações locais das filiais e de atores externos locais (governos, sindicatos, institutos de pesquisa, universidades), que podem fornecer às subsidiárias melhores condições de reivindicar a descentralização de tais atividades.

Finalmente, é preciso frisar que, a partir da análise do campo, parece-nos que nenhum dos aspectos associados às proposições pode por si só levar à descentralização das atividades de inovação. O estabelecimento da estrutura de P, D \& E local depende da conjunção dos fatores presentes nas proposições: estratégia da companhia, atributos da filial, relacionamento matriz-filial, além de outros elementos não tratados neste texto (como os incentivos governamentais, relações com institutos de P \& D e universidades) e que deverão ser mais bem investigados em outras pesquisas. 


\title{
Decentralization of Research, Development and Engineering activities in transnational corporations: contributions to theory from a subsidiary perspective
}

\begin{abstract}
The decentralization of Research, Development, and Engineering $-R, D \& E$ activities towards subsidiaries in transnational companies have been justified due to market conditions and access to scarce resources such as technology. Such analysis has been made on the basis of research performed in central countries - that is, a transnational central country-based company which is setting up a $R, D \& E$ center in another central country. The analysis does not explain adequately cases of $R, D \& E$ location in emergent countries, as it is the case of Brazil. This paper proposes a theoretical models improvement in order to explain the decentralization of $R, D \& E$ towards subsidiaries based on an in-depth research conducted in the Brazilian automotive industry. Besides traditional explanation, market proximity, and technology sourcing, it can be said that the decentralization of $R, D \& E$ activities towards subsidiaries is influenced by the need of achieving agility in the product development process and by the quality of the relationship between the headquarters and subsidiary.
\end{abstract}

Keywords: $R \&$ D. Product development. Product development decentralization. Innovation. Automotive industry. Emergent countries.

\section{Referências}

ASSOCIAÇÃO NACIONAL DOS FABRICANTES DE VEÍCULOS AUTOMOTORES - ANFAVEA. Anuário estatístico da indústria automobilística brasileira. São Paulo, 2002.

ASSOCIAÇÃO NACIONAL DOS FABRICANTES DE VEÍCULOS AUTOMOTORES - ANFAVEA. Estatísticas. Disponível em: $<$ http://www.anfavea.com.br/tabelas2001.html $>$. Acesso em: 10 de Setembro de 2008.

BARTLETT, C.; GHOSHAL, S. Gerenciando empresas no exterior: a solução transnacional. São Paulo: Makron Books, 1992.

BERNOUX, P. La sociologie des organisations. Paris: Éditions du Seuil, 1990.

BIRKINSHA, W. J.; HOOD, N. Multinational subsidiary evolution: capability and charter change in foreign-owned subsidiary companies. Academy of Management Review, v. 23, n. 4, p. 773-795, 1998.

BRASIL. Ministério do Desenvolvimento, Indústria e Comércio Exterior. Política de Desenvolvimento Produtivo. Brasília, 2008.

BRUCE, M.; DALY, L.; KAHN, K. Delineating design factors that influence the global product launch process. Journal of Product Innovation Management, v. 24, n. 5, p. 456-470, 2007.

BRYMAN, A. Research methods and organization studies. London: Routledge, 1989.

CHIESA, V. Global R\&D project management and organization: a taxonomy. Journal of Product Innovation Management, v. 17, n. 5 , p. 341-359, 2000.

CONSONI, F. Da tropicalização ao projeto de veículos: um estudo das competências em desenvolvimento de produtos nas montadoras de automóveis no Brasil. 2004. 267f. Tese (Doutorado em Política Científica e Tecnológica) - Instituto de Geociências, Universidade Estadual de Campinas, Campinas.

CLARK, K. B.; FUJIMOTO, T. Product development performance: strategy, organization and management in the world auto industry. Boston: Harvard Business School Press, 1991.
CLARK, K. B.; WEELWRIGHT, S. C. Managing new product and process development. New York: Fress Press, 1993.

CUSUMANO, M. A.; NOBEOKA, K. Le management multi-projets: optimiser le développement des produits. Paris: Dunod, 1999.

DRUCKER, P. Introdução à administração. São Paulo: Pioneira, 1998.

DUNNING, J. H. Multinational enterprises and the global economy. Harlow: Addison-Wesley, 1993.

EISENHARDT, K. Building theories from case study research. Academy of Management Review, v. 14, n. 4, p. 532-550, 1989.

FERDOWS, K. Making the most of foreign factories. Harvard Business Review, v. 75, n. 2, p. 73-88, 1997.

FLEURY, A. The changing pattern of operations management in developing countries: the case of Brazil. International Journal of Operations and Production Management, v. 19, n. 5-6, p. 552-564, 1999

FLEURY, A.; FLEURY, M. T. Estratégias empresariais e formação de competências: um quebra-cabeça caleidoscópico na indústria brasileira. São Paulo: Atlas, 2006.

FLORIDA, R. The globalization of R\&D: results of a survey of foreign-affiliated R\&D laboratories in the USA. Research Policy, v. 26, n. 1, p. 85-103, 1997.

GAMMELGAARD, J. How foreign subsidiaries develop into integrated competence centres. Copenhagen: Copenhagen Business School, 1999. Working Paper WP 13.

GASSMANN, O.; Von ZEDTWITZ, M. New concepts and trends in international R\&D organization. Research Policy, v. 28, n. 2-3, p. 231-250, 1999.

GERPISA. GERPISA Réseau International. Disponível em: <www. gerpisa.univ-evry.fr>. Acesso em: 10 de Setembro de 2008.

GIARD, V. Les gestions du risque dans les projets. In: GIARD, V.; MIDLER, C. (Dir.). Pilotages de projet et entreprises: diversités et convergences. Paris: Economica, 1993. 
GIARD, V.; LOCHERER, C.; VERGNENÈGRE, A. Le temps dans la gestion des projets. In: GIARD, V.; MIDLER, C. (Dir.). Pilotages de projet et entreprises: diversités et convergences. Paris: Economica, 1993.

HARVEY, M.; GRIFFITH, D. The role of globalization, time acceleration and virtual global teams in fostering successful global product launches. Journal of Product Innovation Management, v. 24, n. 5 , p. 486-501, 2007.

LEVITT, T. The globalization of markets. Harvard Business Review, v. 61, n. 3, p. 92-102, 1983.

McDONOUGH III, E.; KAHN, K.; BARCZAK, G. An investigation of the use of global, virtual and colocated new product development teams. Journal of Product Innovation Management, v. 18, n. 2, p. 110-120, 2001.

McDONOUGH III, E.; KAHN, K.; GRIFFIN, A. Managing communication in global product development teams. IEEE Transactions on Engineering Management, v. 46, n. 4, p. 375-386, 1999.

MEDCOF, J. A taxonomy of internationally dispersed technology units and its application to management issues. R\&D Management, v. 27, n. 4, p. 301-318, 1997.

MIDLER, C. L'auto qui n'existait pas: management des projets et transformation de l'entreprise. Paris: InterEditions, 1993.

MINTZBERG, $\mathrm{H}$. The rise and fall of strategic planning. New York: The Free Press, 1994. Crafting strategy. Harvard Business Review, v. 65, n. 10 , p. 66-76, 1987.

Structure in fives: designing effective organizations. Englewood Cliffs; New Jersey: Prentice Hall, 1983.

MIOTTI, L.; SACHWALD, F. Patterns of R\&D cooperation by european firms: cost-economizing versus technology-seeking. In: AITEG WORKSHOP. Annals...Madrid: AITEG, 2001. p. 1-30.

MORGAN, G. Imagens da organização. São Paulo: Atlas, 1996.

MUDAMBI, R.; MUDAMBI, S.; NAVARRA, P. Global innovation in MNCs: the effects of subsidiary self-determination and teamwork. Journal of Product Innovation Management, v. 24, n. 5, p. 442-455, 2007.

MUFFATTO, M. Platform strategies in international new product development. International Journal of Operations and Production Management, v. 19, n. 5-6, p. 449-459, 1999.

PRAHALAD, C. K.; HAMEL, G. The core competence of the corporation. Harvard Business Review, v. 68, n. 3, p. 79-91, 1990.
QUADROS, R.; QUEIROZ, S. The implications of globalisation for the distribution of design competencies in the auto industry in Mercosur. In: EME RENCONTRE INTERNATIONALE, 8, GERPISA. Actes... Paris: Editora Université d'Évry, 2000.

REDDY, P. New trends in globalization of corporate R\&D and implications for innovation capability in host countries: a survey from India. World Development, v. 25, n. 11, p. 1821-1837, 1997.

ROBERTSON, D.; ULRICH, K. Planning for product platforms. Sloan Management Review, v. 40, n. 1, p.19-31, 1998.

SALERNO, M. S. et al. Política industrial em setores dominados por transnacionais: o Brasil como sede de concepção e projeto de produto. In: FLEURY, A.; FLEURY, M. T. L. (Orgs.). Política industrial 2. São Paulo: Publifolha, 2004. p. 67-91. Coleção Biblioteca Valor.

SALERNO, M. S. et al. A nova configuração da cadeia de fornecimento na indústria automobilística no Brasil. Revista de Administração, v. 38, n. 3, p. 192-204, 2003.

SINDIPEÇAS. Desempenho do setor de autopeças. Disponível em: <http://www.sindipecas.org.br>. Acesso em: 20 de Março de 2003.

STALK Jr., G. Time: the next source of competitive advantage. In: MONTGOMERY, C.; PORTER, M. (Eds.). Strategy: seeking and securing competitive advantage. Boston: Harvard Business School Press, 1991.

VELTZ, P. Le nouveau monde industriel. Paris: Gallimard, 2000.

VERGANTI, R. Planned flexibility: linking anticipation and reaction in product development projects. Journal of Product Innovation Management, v. 16, n. 4, p. 363-376, 1999.

WOMACK, J.; JONES, D.; ROOS, D. A máquina que mudou o mundo. Rio de Janeiro: Campus, 1997.

VON ZEDWITZ, M.; GASSMANN, O. Market versus technology drive in R\&D internationalization: four different patterns of managing research and development. Research Policy, v. 31, n. 4, p. 569-588, 2002.

VOSS, C.; TSIKRIKTSIS, N.; FROHLICH, M. Case research in operations management. International Journal of Operations \& Production Management, v. 22, n. 2, p. 195-219, 2005.

YIN, R. K. Case study research: design and methods. Thousand Oaks: Sage Publications, 1994.

\section{Sobre os autores}

\section{Ana Valéria Carneiro Dias}

Programa de Engenharia de Produção da Escola Politécnica da USP Departamento de Engenharia de Produção da UFMG

Av. Antônio Carlos, 6627, CEP 31270-901, Belo Horizonte, MG, Brasil e-mail: anaval@ufmg.br

\section{Mario Sergio Salerno}

Departamento de Engenharia de Produção da Escola Politécnica da USP Av. Prof. Almeida Prado, travessa 2, n.128, CEP 05508-900, São Paulo, SP, Brasil e-mail: msalerno@usp.br 